\title{
CORONAVÍRUS: REFLEXÕES SOBRE A PANDEMIA
}

\author{
CORONAVIRUS: REFLECTIONS ON THE PANDEMIC
}

\section{Letícia Sousa Oliviera $^{1}$, Samily Linard Neiva Pimenta ${ }^{1}$, Ysla Kallena Macedo e Medeiros ${ }^{1}$, Bianca Caroline da Cunha Geramano ${ }^{2}$ e Dany G. Kramer ${ }^{3}$}

\section{RESUMO}

Os coronavírus são um grupo de vírus envelopados com genomas positivos de RNA de fita simples. Estes têm sido associado a surtos como a SARS, MERS e, mais recentemente, a pandemia pela doença do coronavírus 2019 (COVID-19), acarretando em milhões de infectados e dezenas de milhares de mortes. A doença apresenta desde sintomatologia leve (semelhante a resfriado comum) a grave (complicações respiratórias, renais e cardiológicas). Este trabalho teve como objetivo realizar uma revisão bibliográfica sobre as principais informações sobre COVID-19. Tratou-se de um estudo exploratório do tipo revisão bibliográfica. Os quadros mais brandos do COVID 19 apresentam como sintomas mais comuns tosse seca, febre e mialgia, podendo se agravar, principalmente entre idosos e portadores de comorbidades, levando a complicações renais, cardíacas e respiratórias, apresentando maior taxa de mortalidade nesses grupos. Em relação à infecção intra-uterina, não há ainda relatado na literatura a possibilidade de transmissão vertical. Os atuais tratamentos para COVID-19 envolvem principalmente o uso de antirretrovirais e antimaláricos. Conclui-se que medidas sanitárias para propagação da doença devem ser intensificadas, principalmente entre grupos mais vulneráveis. Estudos sobre a transmissão vertical na gestação devem ser potencializados, bem como aqueles envolvendo esquemas terapêticos, para que os resultados possam ser melhor interpretados e protocolos clínicos possam ser estabelecidos para aplicação no tratamento do COVID-19.

Palavras-chave: COVID-19. Epidemiologia. Tratamento.

\section{ABSTRACT}

Coronaviruses are a group of viruses enveloped with positive single-stranded RNA genomes. These have been associated with outbreaks such as SARS, MERS and, more recently, the 2019 coronavirus disease pandemic (COVID-19), leading to millions of infected people and tens of thousands of deaths. The disease presents from mild symptoms (similar to the common cold) to severe (respiratory, renal and cardiac complications). This work aimed to carry out a bibliographic review on the main information about COVID-19. It was an exploratory study of the literature review type. The milder symptoms of COVID 19 have dry cough, fever and myalgia as the most common symptoms, which can worsen, especially among the elderly and patients with comorbidities, leading to renal, cardiac and respiratory complications, with a higher mortality rate in these groups. Regarding intrauterine infection, the possibility of vertical transmission has not yet been reported in the literature. Current treatments for COVID-19 mainly involve the use of antiretrovirals and antimalarials. It is concluded that sanitary measures to spread the disease must be intensified, especially among the most vulnerable groups. Studies on vertical transmission in pregnancy should be enhanced, as well

\footnotetext{
${ }^{1}$ Acadêmicos do Curso de Medicina - Universidade Federal do Rio Grande do Norte - UFRN. E-mail: leticiasousa777@, gmail.com; linardsamily@gmail.com; yslakallenamm@hotmail.com

${ }^{2}$ Médica. Maternidade Escola Januário Cicco. E-mail: bccgermano3@yahoo.com.br

${ }^{3}$ Prof. Dr. Programa de Pós-Graduação em Saúde da Família. RENASF. Universidade Federal do Rio Grande do Norte - UFRN. E-mail: dgkcs@yahoo.com.br
} 
as those involving therapeutic schemes, so that the results can be better interpreted and clinical protocols can be established for application in the treatment of COVID-19.

Keywords: COVID-19. Epidemiology. Treatment.

\section{INTRODUÇÃO}

Os coronavírus são um grupo de vírus envelopados com genomas positivos de RNA de fita simples que por sua aparência semelhante a uma coroa possuem essa nomenclatura. Nas últimas décadas têm sido responsáveis pelos surtos: Síndrome Respiratória Aguda Grave (SARS) em 2003 e síndrome respiratória do Oriente Médio (MERS) em 2012. Mais recentemente a pandemia do coronavírus 2019 (COVID-19) surgiu em Wuhan, China. (RUFEN et al., 2020; QIU et al., 2020; LFIKY, 2020; DEVAUX et al., 2020)

O Grupo de Estudo para Coronavírus do Comitê Internacional de Taxonomia de Vírus designou o vírus do COVID-19 como síndrome respiratória aguda grave por coronavírus 2 (SARS-CoV-2), caracterizado com alto poder de contágio, a qual, em alguns casos, pode ser rapidamente fatal, sendo necessário medidas de isolamento e de fronteiras de vigilância em todo mundo (LFIKY 2020; YUEN et al., 2020; LIU et al., 2020; CAI et al., 2020).

A Organização Mundial da Saúde (OMS), em 30 de janeiro de 2020, declarou que o surto do SARS-CoV-2 se constituía como uma Emergência de Saúde Pública de Interesse Internacional (PHEIC) que se tornou uma pandemia em 12 de março de 2020 (CAI et al., 2020; LFIKY 2020; GAUTRET et al., 2020).

De acordo com os dados atualizados da European Centre for Disease Prevention and Control (ECDC, 2020), entre 31 de dezembro de 2019 a 30 de maio de 2020, foram relatados 5899866 casos de COVID-19 e 364891 mortes, com maior prevalência de óbitos nos Estados Unidos (102 836), Reino Unido (38 161) e Itália (33 229); e no Brasil 27878 mortes.

A transmissão primária acredita-se ter ocorrido no ambiente natural entre animais, que se contaminaram sendo então, capturados e comercializados no mercado público de Wuhan-China. Na sequência, deve ter ocorrido a transmissão zoonótica, ocorrendo os casos considerados primários. Estes por sua vez, contribuíram com a transmissão secundária, resultante do contato entre o infectado e outras pessoas de seu convívio, sendo considerado como principal via de transmissão o contato com gotículas expelidas (tosse/espirro), podendo ser inaladas ou contaminar mãos, alimentos e objetos (YUEN et al., 2020; CAI et al., 2020; GAUTRET et al., 2020; LIU et al., 2020).

Após o contato inicial, o vírus pode ficar incubado de dois dias a duas semanas, podendo apresentar-se assintomático, sintomatologia semelhante ao resfriado comum (febre, tosse e falta de ar) ou progredir para quadros graves, acarretando em comprometimento respiratório, renal e cardíaco. A pandemia tem afetado mais de 160 países acarretando em milhões de infectados e dezenas de 
milhares de mortes. Até o momento, não existem agentes terapêuticos específicos para infecções por esse coronavírus (CAI et al., 2020; GAUTRET et al., 2020; LIU et al., 2020). Porém, muitos estudos ainda estão sendo feitos para chegar a um tratamento mais eficaz. Dessa forma, este artigo teve como intuito realizar uma revisão sobre as principais características do COVID-19, bem como discorrer sobre o impacto do SARS-CoV-2 em gestantes e crianças, assim como abordar os esquemas terapêuticos recentes.

\section{METODOLOGIA}

O presente artigo caracteriza-se como um estudo exploratório de revisão bibliográfica, cuja base de pesquisa foi Pubmed, Capes e Elsevier, sendo para tanto utilizados os descritores Covid-19; pandemic; endemic e transmission, bem como os filtros "Published: in the last 05 years"; "Species: Humans"; "Year: 2020"; “Type: Article".

Os títulos foram avaliados e descartados com base nos critérios de exclusão: estudos que tratavam das repercussões psicológicas da pandemia do Covid-19, estudos que abordaram a terapêutica de outras condições de saúde no contexto da pandemia; pesquisas com perspectivas futuras e previsões e as que tratavam da disseminação de informações nas redes sociais. Também foram excluídos os títulos que se repetiam entre as diferentes bases de pesquisa.

Em relação aos critérios de inclusão, foram considerados para análise os manuscritos que discorriam sobre a biologia e transmissibilidade do vírus, epidemiologia, clínica, prevenção e tratamento do COVID-19.

As referências selecionadas na etapa de avaliação dos títulos foram analisadas com base nos resumos e posteriormente no fundamento do texto integral, sendo excluídos em cada etapa os artigos que não atendiam aos critérios supracitados ou aos propósitos deste artigo.

Devido à grande produção científica vigente no cenário atual e a entrada constante de novos estudos nas bases de pesquisa, outras referências foram acrescentadas durante a construção desta revisão, as quais foram selecionadas com base nos descritores: COVID-19; SARS-Cov-2; clinical features; epidemiology; risk factors; pregnancy.

\section{SARS-CoV-2}

\section{A - ESTRUTURA, TRANSMISSÃO E REPLICAÇÃO}

O SARS-CoV-2 é um coronavírus pertencente à família Coronaviridae, com formatos esféricos ou pleomórficos, cuja estrutura se assemelha a uma coroa. Apresenta um envelope onde se fixam a glicoproteína S e hemaglutinina, responsáveis pela ligação ao receptor da célula alvo. Em seu 
interior, apresenta o material genético de RNA de fita simples (sentido positivo) (YUEN et al., 2020; CHEN et al., 2020; LINTON et al., 2020).

A disseminação ocorre através do contato próximo com uma pessoa contaminada por meio de gotículas respiratórias, fômites e alimentos contaminados; a exemplo do aperto de mão ou manuseio de objetos possivelmente contaminados como celular, maçanetas de portas e utensílios domésticos. Vale ressaltar que o número básico de reprodução da propagação de pessoa para pessoa é cerca de 2,6, o que significa que os casos infectados com SARS-CoV-2 crescem a uma taxa exponencial, sendo relativamente alto, com tempo de incubação entre 2-14 dias (LIU et al., 2020; CHEN, 2020; VADUGANATHAN et al., 2020.

Após a transmissão o vírus segue para uma célula alvo, iniciando-se a replicação Figura 01, onde a glicoproteína $\mathrm{S}$ se conecta ao receptor célula, isto leva a endocitose viral e internalização em uma vesícula. Nesta, ocorre o desnudamento viral com a liberação do RNA no citoplasma celular, que é codificado, iniciando a transcrição e síntese das estruturas virais. Após a montagem, o vírus é liberado por exocitose, podendo infectar novas células (YUEN et al., 2020; CHEN, 2020; BIALEK et al., 2020).

Figura 01 - Replicação do coronavírus (COVID 19).

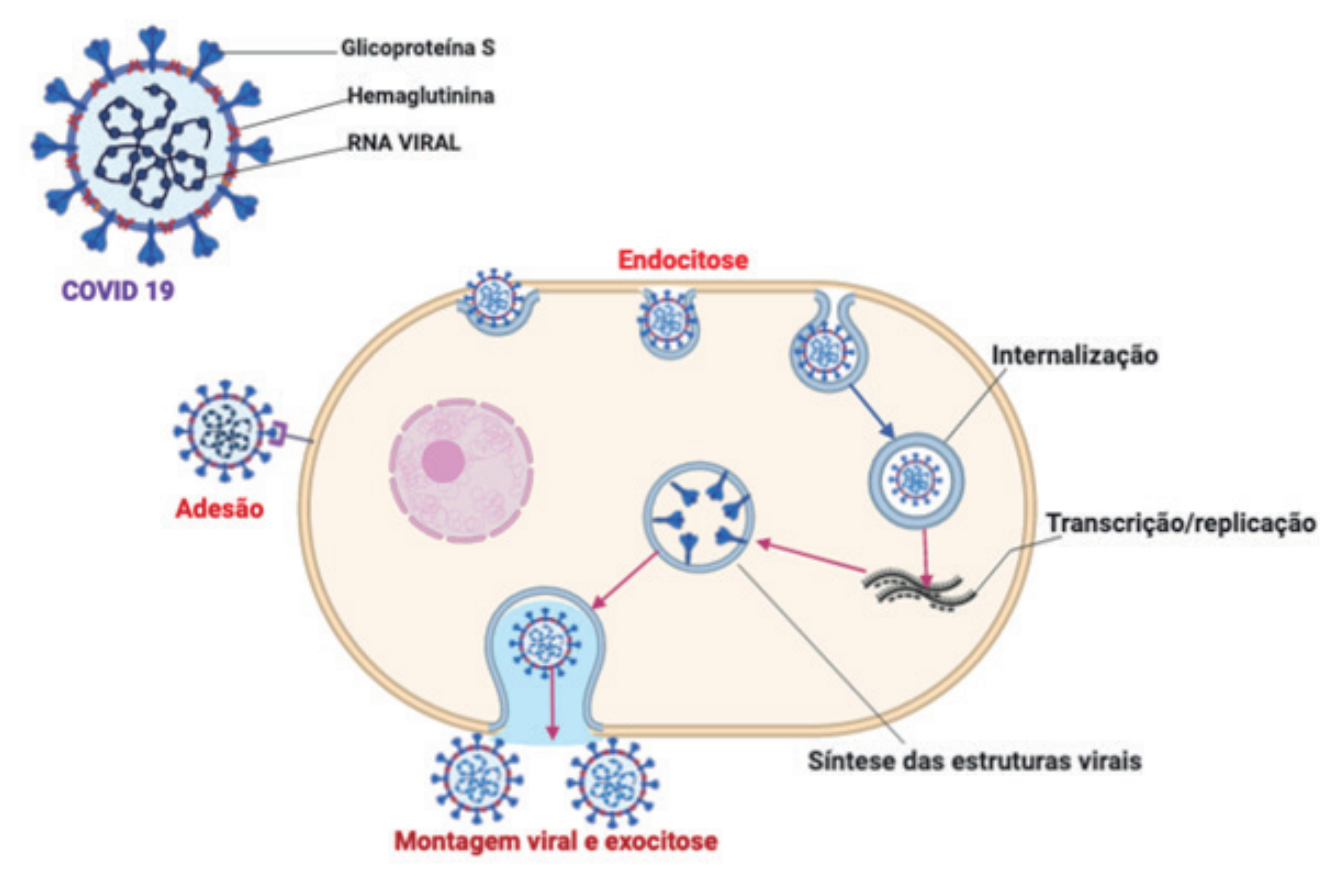

Fonte: Construção do Autor. Produzido em: www.biorender.com.

\section{B - SINTOMATOLOGIA}

Após o contato inicial com o vírus, ocorre o período de incubação, que varia de 2 a 14 dias. Durante esse intervalo de tempo, algumas pessoas podem desenvolver a forma assintomática do COVID-19, porém, por outro lado, outros podem ter sintomas semelhantes a um resfriado, sendo os 
sintomas mais comuns: tosse seca e febre. (QIU et al., 2020; LIU et al., 2020). Além disso, podem ser observados congestão faríngea, fadiga, cefaleia e mialgia. Em pacientes idosos ou em portadores de comorbidades, como doenças cardiovasculares, diabetes e imunossupressão, os quadros podem evoluir para insuficiência respiratória e pneumonia, que necessitam de internação, levando a complicações cardiovasculares, infecções secundárias e problemas renais (GAUTRET et al., 2020; LIU et al., 2020).

De acordo com um estudo recente da China, cerca de $80 \%$ dos pacientes apresentam de doença leve e autolimitada do trato respiratório a pneumonia progressiva grave, falência de vários órgãos e morte, com taxa geral de letalidade de 2,3\%. Tais complicações atingem 8,0\% dos pacientes com idades entre 70 e 79 anos e 14,8\% dos pacientes maiores de 80 anos (GAUTRET et al., 2020; LIU et al., 2020).

Um relatório lançado pelo ECDC dos Estados Unidos com 4226 casos de pacientes diagnosticados com COVID-19, entre 12 de fevereiro e 16 de março de 2020, apontou que $31 \%$ dos casos, $45 \%$ das internações, $53 \%$ das internações em UTI e $80 \%$ das mortes ocorreram em adultos com idade $\geq 65$ anos, com o maior percentual de resultados graves entre pessoas com idade $\geq 85$ anos, semelhante aos dados supracitados da China (BIALEK et al., 2020).

O Centro Chinês de Controle e Prevenção de Doenças, em um relatório de 72.314 casos de COVID-19, apresentou um aumento da mortalidade de 7,3\% em pessoas com diabetes verso a mortalidade de 2,3\% em pessoas sem comorbidades (SINGH et al., 2020).

Somado a isso, Vaduganathan et al. (2020) apontaram que os hipertensos estão sendo o grupo mais comum entre os pacientes com COVID-19 que sofrem com a doença grave ou que foram a óbito. Corroborando com tal assertiva, segundo um estudo de Cummings et al. (2020), dos 257 pacientes com quadro mais crítico, 212 (82\%) possuíam pelo menos uma doença crônica, sendo as mais comuns hipertensão (63\%) e diabetes (36\%).

Neste contexto, de forma geral, a mortalidade por COVID-19 é especialmente alta entre pacientes com comorbidades, tais como: hipertensão, diabetes, doenças cardiovasculares doença renal crônica ou câncer (CHEN et al., 2020).

Já as crianças com COVID-19 apresentam manifestações clínicas mais leves, podendo em grande parte ser assintomáticas (QIU et al., 2020).

Nas mulheres grávidas, o SARS-CoV e o MERS-CoV podem resultar em maus resultados obstétricos, tais como ruptura prematura de membranas e trabalho de parto prematuro, morte fetal intrauterina, restrição de crescimento intrauterino e morte neonatal; incluindo morbidade e a morte materna; porém os efeitos do COVID-19 em mulheres grávidas ainda estão sendo pesquisado (SCHWARTZ et al., 2020; GAUTRET et al., 2020).

Os indivíduos assintomáticos corroboram com a superestimação da taxa de mortalidade e para a sua disseminação, uma vez que se observam na maioria dos países o crescimento geométrico diário de casos notificados (SCHWARTZ et al., 2020; GAUTRET et al., 2020). Sob essa ótica, medidas de restrição de convívio social, fechamento de comércios, proibição de viagens e reforços nas 
medidas de proteção e higiene pessoal são necessárias, buscando reduzir a propagação da doença e sobrecarga nos sistemas de saúde.

\section{C - EPIDEMIOLOGIA}

O SARS-CoV-2 vem sendo comparado na comunidade científica às síndromes respiratórias anteriormente enfrentadas pelos seres humanos: SARS e MERS. Nessa perspectiva, através de uma análise de dados entre alguns casos confirmados para COVID-19, observando o período de incubação do SARS-COV-2, encontrou-se uma média compatível com as duas outras enfermidades supracitadas. Neste estudo foi visto que o período de incubação varia dentro de uma faixa que vai de 2 a 14 dias, fato que corrobora as atuais medidas de isolamento por 14 dias preconizadas pela Organização Mundial de Saúde frente a um caso suspeito para COVID-19 (SINGH et al, 2020; LINTON et al., 2020).

No início da epidemia do SARS-CoV-2 houve uma subestimação da real fatalidade do vírus entre a população e isso foi decorrente da média do tempo entre o aparecimento dos sintomas e o falecimento do indivíduo que foi de 15 a 20 dias, (LINTON et al., 2020), corroborando para que a medidas restritivas tivesse menor adesão nos dias iniciais. Essa média está de acordo com um estudo com 191 pacientes internados em hospitais em Wuhan, para os quais o tempo médio desde o início da doença até a morte dos pacientes foi de 18,5 dias, variando entre 15 e 22 dias (ZHOU et al., 2020). Outro estudo que contribui com essa afirmação foi feito com 274 pacientes, para os quais esta média foi de 16 dias, variando entre 12 e 20 dias (CHEN-TAO et al., 2020). Essa informação permite justificar a descrença da população durante os períodos iniciais da epidemia sobre a possível gravidade da COVID-19, o que pode ter favorecido a disseminação do vírus.

O estudo de Guan et al., 2020, analisaram 1099 pacientes confirmados de COVID-19 em laboratório de 552 hospitais em 30 províncias, regiões autônomas e municípios da China de 2019 a janeiro 2020; 6,1\% destes pacientes tiveram um desfecho mais crítico: admissão em uma unidade de terapia intensiva (UTI), o uso de ventilação mecânica ou a morte. Percebeu-se que uma pequena porcentagem dos indivíduos infectados evoluem com um quadro crítico, como é descrito no sumário de um relatório de 44672 casos confirmados do Centro Chinês de Controle e Prevenção de Doenças, resumido na Tabela 1 (WU et al., 2020).

No estudo de Zhou et al., (2020) entre os 191 pacientes internados em estado crítico, 97\% destes necessitaram de ventilação mecânica e vieram à óbito. Cummings et al. (2020) realizou um estudo em dois hospitais em Nova York (NY, EUA) nos quais, entre 1150 pacientes internados, 257 (22\%) eram pacientes gravemente enfermos com COVID-19 confirmado, dentre estes 203 (79\%) precisaram de ventilação mecânica e 84 (41\%) destes faleceram. Dessa maneira, sugere-se que, apesar de os quadros mais graves serem uma minoria, eles são os mais associados à mortalidade no COVID-19, 
corroborando com o relatório do Wu et al., (2020), cuja a incidência de internação na UTI de casos críticos entre os pacientes variou de 7 a $26 \%$.

Tabela 1 - Epidemiologia do COVID-19 em 44672 casos na China (WU et al., 2020).

\begin{tabular}{ccc}
\hline Distribuição de idade & Espectro de gravidade & Taxa de fatalidade \\
\hline$\geq 80$ anos: $3 \%$ (1408 casos) & Leve: $81 \%$ (36 160 casos) & $2.3 \%$ (1023/ 44672 casos confirmados) \\
$30-79$ anos: $87 \%$ (38 680 casos) & Severa: $14 \%$ (6168 casos) & $14.8 \%$ em pacientes $\geq 80$ anos $(208 / 1408)$ \\
$20-29$ anos: $8 \%$ (3619 casos) & $8.0 \%$ em pacientes $70-79$ anos (312/3918) \\
$10-19$ anos: $1 \%$ (549 casos) & Crítica: $5 \%$ (2087 casos) & $49.0 \%$ em casos críticos (1023/2087) \\
$<10$ anos: $1 \%$ (416 cases) & \multicolumn{2}{c}{ Fonte: Construção do Autor }
\end{tabular}

As referências têm destacado a idade como um fator associado à mortalidade da doença. $\mathrm{O}$ estudo de Cummings et al., (2020) apontou que os 257 pacientes gravemente enfermos possuíam idade média de 62 anos e destes 101 (39\%) morreram após uma mediana de 9 dias. De modo semelhante, outro estudo com 274 pacientes, dos quais 113 vieram a óbito, demonstrou que $83 \%$ dos falecimentos ocorreu entre os pacientes com idade igual ou acima de 60 anos. (CHEN-TAO et al., 2020). Ademais, no estudo com 191 pacientes hospitalizados, a idade média dos pacientes infectados foi 56 anos e, entre os 54 pacientes que vieram à óbito, a idade variou entre 63 e 76 anos (ZHOU et al., 2020).

Tal estudo de Zhou et al., (2020) ainda destacou que defeitos na função das células T e células $\mathrm{B}$ dependentes da idade e o excesso de produção de citocinas tipo 2 podem levar à uma deficiência no controle da replicação viral e às respostas pró-inflamatórias mais prolongadas, potencialmente levando a um desfecho ruim. Isto justifica a atual preocupação social referente a esse grupo de indivíduos e a disseminação de informações relacionadas a necessidade de isolamento social principalmente por parte de todos os idosos e dos indivíduos com déficits imunológicos.

Face às características clínicas dos pacientes com COVID-19, a febre foi relatada em todos os estudos revisados como sendo a mais comum do sintoma, todavia estava mais presente em pacientes internados, com uma porcentagem acima de 80\% (ZHOU et la., 2020; CHEN-TAO et al., 2020; WU et al., 2020). Entretanto, ainda nessa temática, um dos estudos revela que mais da metade dos pacientes que ainda não tinham sido admitidos para internação não apresentaram febre como sintoma diferencial (GUAN et al., 2020), reforçando o quanto a vigilância sobre a temperatura corporal da população não é um dos métodos mais eficazes para triagem dos casos leves, sobretudo porque os estão em grupos de risco e eles possuem uma tendência em apresentar quadros atípicos das doenças, de modo que muitas vezes não apresentam febre. Por outro lado, consoante o estudo de Cummings et al., (2020), a febre foi o segundo sintoma mais comum entre os pacientes gravemente enfermos, tendo um total de 183/257 (71\%) pacientes internados com febre.

A tosse, por sua vez, foi relatada por todas as referências analisadas e, grande parte, como o segundo sintoma mais presente entre os indivíduos, com porcentagens variando de $48,2 \%$ a $88 \%$ 
dos pacientes destes estudos (ZHOU et al., 2020; CHEN-TAO et al., 2020; GUAN et al., 2020, LIU-KUI et al., 2020). Essas porcentagens, quase sempre maioritárias, indicam que a maior dos pacientes pode apresentar essa sintomatologia, mas a sua ausência não exclui a suspeita de contaminação pelo novo coronavírus.

Outro sintoma que tem sido bastante associado à infecção por SARS-CoV-2 é a dispneia, a qual, de fato, esteve presente entre os pacientes dos estudos avaliados. No entanto, sua prevalência foi maior entre os pacientes com quadro clínico grave, principalmente entre os que vieram a falecer. Num estudo com 274 pacientes, por exemplo, ela foi descrita para 62\% dos 113 pacientes que vieram ao óbito e por $31 \%$ dos 161 pacientes que sobreviveram, indicando que a falta de ar foi mais comuns entre os pacientes que faleceram quando comparado aos recuperados. (CHEN-TAO et al., 2020). Assim como, em outro estudo com 257 pacientes com quadro clínico mais severo, 190 (74\%) apresentou dispneia, sendo o achado mais comum entre eles (CUMMINGS et al., 2020).

\section{D - DIAGNÓSTICO}

Dentre os exames complementares realizados nos pacientes dos estudos, a TC de tórax, foi o principal exames de imagem realizado nos indivíduos positivos para COVID-19, e em todos os estudos analisados envolvendo essa temática encontrou-se anormalidades nas imagens na maioria dos pacientes, sendo descrita principalmente a opacidade bilateral em vidro fosco como o achado mais comum (ZHOU et al., 2020; CHEN-TAO et al., 2020; GUAN et al., 2020, LIU-KUI et al., 2020). Em um dos estudos, dentre 5 pacientes internados em estado grave, 4 possuíam opacidade em vidro fosco (BHATRAJU et al., 2020). Este mesmo achado estava presente em 84,7\% dos indivíduos do estudo com 137 pacientes (LIU-KUI et al., 2020).

Com relação aos exames laboratoriais realizados em indivíduos positivos para COVID-19, as referências analisadas também estão de acordo para achados de linfocitopenia em grande parte dos pacientes analisados em seus estudos, com porcentagens variando entre 40\% e 83\% (ZHOU et al., 2020; CHEN-TAO et al., 2020; GUAN et al., 2020, LIU-KUI et al., 2020).

Além disso o estudo feito com os 191 pacientes internados, evidenciou que a linfocitopenia estava presente em $76 \%$ dos pacientes que vieram à óbito e em apenas $26 \%$ dos pacientes que sobreviveram e, neles, a contagem de linfócitos melhorou durante a hospitalização. Um achado semelhante foi observado no estudo com 274 pacientes internados, no qual a linfocitopenia estava presente em 91\% dos pacientes que faleceram e em $47 \%$ dos que se recuperaram. Ainda, nestes pacientes a diminuição do número de linfócitos no sangue se apresentou mais persistente e mais severa do que nos pacientes que se recuperaram (CHEN-TAO et al., 2020; ZHOU et al., 2020). Isto sugere que um estado de imunodeficiência celular foi associado a um mau prognóstico. Os achados clínicos de maior destaque nos pacientes das referências analisadas estão resumidos na Tabela 2. 
A maioria dos pacientes também apresentou níveis elevados de proteína C-reativa no estudo que contou com 1099 pacientes (GUAN et al., 2020), mas não foi especificado o valor exato para o achado; todavia o estudo feito com 137 pacientes encontrou 83,9\% dos pacientes com proteína C reativa elevada (LIU-KUI et al., 2020), bem como em outro estudo com 257 pacientes em estado grave, 253 (98\%) possuíam essa proteína aumentada (CUMMINGS et al., 2020).

Outro achado comum entre os estudos foi a elevação do D-dímero, principalmente nos pacientes com quadros mais graves. Num estudo com 274 pacientes, as concentrações do D-dímero foram marcadamente maiores nos pacientes que faleceram do que nos que se recuperaram (CHEN-TAO et al., 2020). Também no estudo de Cummings et al., (2020), dos 257 pacientes internados, 244 (95\%) tiveram o D-dímero aumentado. Ademais, corroborando com estes achados, o estudo com 191 pacientes concluiu que níveis de D-dímero maiores do que $1 \mu \mathrm{g} / \mathrm{mL}$ estavam associados a um maior risco de morte (ZHOU et al., 2020).

Tabela 2 - Principais achados clínicos em pacientes com COVID-19.

\begin{tabular}{|c|c|c|c|c|c|c|}
\hline \multirow[b]{2}{*}{ Referência } & \multirow[b]{2}{*}{$\begin{array}{l}\text { Liu-Fang } \\
\text { et al., (2020) }\end{array}$} & \multirow[b]{2}{*}{$\begin{array}{l}\text { Gautret } \\
\text { et al., (2020) }\end{array}$} & & \multirow[b]{2}{*}{$\begin{array}{l}\text { Vaduganathan } \\
\text { et al., (2020) }\end{array}$} & \multirow[b]{2}{*}{$\begin{array}{l}\text { Cummings } \\
\text { et al., (2020) }\end{array}$} \\
\hline & & & $\begin{array}{l}\text { Chen, } \\
(2020)\end{array}$ & $\begin{array}{l}\text { Cao et al., } \\
\text { (2020) }\end{array}$ & & \\
\hline Amostra (n) & 1099 & 137 & 191 & 24 & 274 & 257 \\
\hline Média de idade & 47 & 57 & 56 & 64 & 62 & 62 \\
\hline Febre & $43,8 \%$ & $81,8 \%$ & $94 \%$ & $50 \%$ & $91 \%$ & $71 \%$ \\
\hline Tosse & $67,8 \%$ & $48,2 \%$ & $79 \%$ & $88 \%$ & $68 \%$ & $66 \%$ \\
\hline Mialgia & $14,9 \%$ & \multirow{2}{*}{$32,1 \% * *$} & $15 \%$ & - & $22 \%$ & $26 \%$ \\
\hline Fadiga & $38,1 \%$ & & $23 \%$ & - & $50 \%$ & - \\
\hline Dispneia & $18,7 \%$ & $19 \%$ & - & $88 \% * * *$ & $44 \%$ & $74 \%$ \\
\hline Diarreia & $3,8 \%$ & $8 \%$ & $5 \%$ & - & $28 \%$ & $12 \%$ \\
\hline Alterações na TC de tórax & $86,2 \% *$ & $84,7 \%$ & $71 \%$ & $80 \% * * * *$ & - & - \\
\hline Linfocitopenia & $83,2 \%$ & $72,3 \%$ & $40 \%$ & $75 \%$ & $65,3 \%$ & $89 \%$ \\
\hline \multicolumn{7}{|c|}{ Fonte: Construção do Autor } \\
\hline \multicolumn{7}{|c|}{$\begin{array}{l}\text { * Foram analisadas as tomografias de 975, das quais } 840 \text { continham alterações. } \\
\text { ** O estudo apresenta uma só porcentagem correspondente aos dois sintomas. }\end{array}$} \\
\hline
\end{tabular}

\section{E - CONTAMINAÇÃO NA GRAVIDEZ E NOS NEONATOS}

As gestantes são consideradas um grupo vulnerável, tendo em vista as alterações fisiológicas e as suscetibilidades a infecções com base no comprometimento das suas funções imunológicas no período gravídico, e principalmente a susceptibilidade a patógenos respiratórios e a pneumonia grave, apesar disto, as evidências até o presente momento são elusivas quanto à definição das gestantes como grupo de risco para infecção pelo COVID-19, face à isto, é importante a manutenção da cautela com este grupo (LIU et al., 2020; SCHWARTZ et al., 2020). 
Em um estudo realizado com 59 pacientes, sendo 41 gestantes, divididas em dois grupos: com diagnóstico laboratorial e com diagnóstico clínico para COVID-19. A análise de pacientes com resultado laboratorial (RT-PCR) negativo, mas com clínica favorável foi feita devido aos possíveis falsos negativos presentes. Investigou-se aspectos envolvendo a manifestação de sintomas entre as pacientes, sendo observado que a febre, um sintoma típico e importante método de triagem para casos suspeitos na China não foi observado na maioria das gestantes, pois o sintoma estava presente em apenas $44 \%$ daquelas com diagnóstico laboratorial e 36\% das gestantes com diagnóstico clínico, o que pode-se implicar que existe maior dificuldade em realizar vigilância nas gestantes para identificação de um possível caso suspeito (LIU et al., 2020).

Foi observado nos exames de tomografia computadorizada (TC) a presença de opacidade em vidro fosco como principal alteração nas gestantes, achado comum para COVID-19. Com as informações, a TC poderia ser considerada uma ferramenta eficiente para a detecção precoce dos pacientes com COVID-19 (LIU et al., 2020). Pode-se inferir que pacientes com diagnóstico laboratorial e pacientes com evidência clínica unida a TC com alterações podem ser tratados da mesma forma.

A análise da possibilidade de transmissão vertical realizada em 9 gestantes com testes positivos para COVID-19 revelou que não houve casos de infecção no neonato e as evidências demonstraram a ausência de isolados virais no líquido amniótico, sangue do cordão umbilical, leite materno e na coleta de secreção oral do neonato. Todos os recém nascidos foram testados negativos para a doença (BHATRAJU et al., 2020; CHEN-HUI et al., 2020).

Outro estudo realizado com 19 neonatos cujas mães foram diagnosticadas com COVID-19 demonstrou que nenhum neonato desenvolveu evidências clínicas, radiológicas, hematológicas ou bioquímicas para a doença do novo coronavírus 19 (LIU-WEI et. al 2020). Contribuindo para esses achados, 7 gestantes, admitidas no Hospital Tongji na China com diagnóstico positivo foram acompanhadas em seus partos e os recém nascidos foram observados, alguns realizaram teste RT-PCR e apenas 1 deles foi positivo 36 horas após nascimento, todavia não se pode concluir transmissão vertical nesse caso, haja vista a negatividade nos exames feitos na placenta e cordão umbilical para SARS-COV-2. (YU et al., 2020).

Esses dados contribuem para as atuais evidências da transmissibilidade negativa entre mãe e feto. Entretanto, todos os estudos descritos acima concordam que há necessidade de maiores observações em grávidas diagnosticadas no primeiro trimestre de gestação. Apesar disso com base na experiência anterior com mulheres grávidas que desenvolveram MERS e SARS nunca houve transmissão intra-uterina confirmada de coronavírus da mãe para o feto (SCHWARTZ et al., 2020).

\section{F -TERAPÊUTICA}

O recente surgimento do novo coronavírus colocou em alerta toda a população, principalmente a comunidade científica, tendo em vista o pouco conhecimento a respeito do vírus. Nessa conjuntura, 
a busca de tratamentos eficazes a base de medicamentos torna-se uma corrida contra o tempo e contra o seu potencial de fatalidade entre os indivíduos em grupos de riscos (YUEN et al, 2020).

Alguns dos medicamentos que tem se destacado neste cenário são os antirretrovirais já utilizados para o tratamento do HIV, sobre os quais já se conhece a segurança e o perfil de efeitos adversos. Em um ensaio clínico randomizado, controlado e aberto foi pesquisada a eficácia e a segurança da associação Lopinavir (LPV)/ Ritonavir (RTV) por via oral no tratamento da infecção por SARS-CoV-2. O estudo contou com 199 pacientes adultos internados em um hospital de Wuhan com COVID-19 grave, dos quais 99 receberam o tratamento antiviral em adição ao tratamento padrão e 100 receberam o tratamento padrão isoladamente. Os resultados demonstraram que não houve benefício com o tratamento com lopinavir-ritonavir além do tratamento padrão. Uma das limitações deste estudo pode ter sido o fato de que as cargas virais da garganta foram um pouco mais altas no grupo LPV / RTV, o que sugere que este grupo teve mais replicação viral (CAO et al., 2020).

Apesar disso, resultados diferentes foram encontrados em outro ensaio clínico, no qual foi avaliada a eficácia do Fapinavir (FPV), aplicado em 35 pacientes, em comparação à combinação LPV / RTV usada em 45 pacientes do grupo controle. Neste estudo o LPV / RTV apresentou resultados positivos no tratamento do Covid-19, entretanto, o FPV apresentou uma depuração viral mais rápida e uma maior taxa de melhora na imagem do tórax, sugerindo que ele tem efeitos de tratamento significativamente melhores no COVID-19 em comparação com o LPV / RTV (CAI et al., 2020).

Outro tratamento que demonstrou potencial no início da pandemia é o uso dos antimaláricos cloroquina e hidroxicloroquina, tendo em vista os resultados positivos a respeito da atividade destes fármacos contra a infecção por SARS-CoV-2 in vitro (YAO et al., 2020). Atualmente existem alguns estudos que avaliam a eficácia destes fármacos no tratamento de pacientes diagnosticados com COVID-19 na China, mas os resultados têm se mostrado controversos.

Um ensaio clínico aberto e não randomizado conduzido na França apresentou resultados referentes a 36 pacientes franceses com COVID-19 confirmado laboratorialmente. Destes, 20 foram tratados com hidroxicloroquina ou com a associação hidroxicloroquina/azitromicina e 16 fizeram parte do grupo controle. Após 6 dias, 70\% dos pacientes tratados com hidroxicloroquina apresentaram resultados negativos de PCR em amostras nasofaríngeas (sendo este considerado o critério de cura virológica) comparado a $12,5 \%$ do grupo controle. Além disso, a combinação hidroxicloroquina/ azitromicina se demonstrou superior, pois $100 \%$ dos pacientes tratados com esta combinação foram curados virologicamente comparado a 57,1\% em pacientes tratados apenas com hidroxicloroquina (GAUTRET et al., 2020).

Apesar disso, novos estudos têm refutado estes resultados positivos. Um coorte retrospectivo multicêntrico contou com 1438 pacientes com COVID-19 confirmada, admitidos em 25 hospitais da cidade de Nova Iorque. A amostra foi subdividida em 4 grupos de acordo com o esquema farmacológico utilizado: hidroxicloroquina isolada, azitromicina isolada, hidroxicloroquina com azitromicina 
e nenhuma das drogas. Na análise primária, mesmo após ajustes em relação a situação demográfica, condições pré-existentes e gravidade da doença dos pacientes nos grupos, não foi encontrada diferença significativa na mortalidade durante a hospitalização entre os 3 grupos que receberam tratamento farmacológico e o grupo que não recebeu. Além disso, uma maior proporção de pacientes recebendo o esquema hidroxicloroquina com azitromicina apresentaram parada cardíaca e achados anormais no eletrocardiograma (ROSENBERG et al., 2020).

Resultados semelhantes foram observados em uma análise de registros multinacional que incluiu 96032 pacientes de 671 hospitais ao redor do globo. Destes, 14888 pacientes foram divididos entre 4 grupos de tratamento: cloroquina isolada, cloroquina com macrolídeo, hidroxicloroquina isolada e hidroxicloroquina com macrolídeo, os 81144 pacientes restantes compuseram o grupo controle. Neste estudo, também, não foram encontradas diferenças significativas entre os grupos, de modo que o regime com hidroxicloroquina ou cloroquina (com ou sem macrolídeo) não foi associada a nenhum benefício evidente; ao invés disso, o tratamento com estes fármacos foi associado com risco aumentado de arritmias ventriculares e maior taxa de morte durante a hospitalização (MEHRA et al., 2020).

Esta ausência de benefícios evidentes com a administração destes fármacos também foi encontrada no estudo de Tang et al., (2020) de um ensaio clínico aberto, randomizado e controlado, feito com 150 pacientes com COVID-19. Neste estudo, 148 pacientes apresentavam um quadro clínico de leve a moderado e 109 atingiram conversão negativa do SARS-CoV-2, sendo este o objetivo primário definido pelo estudo. Destes 109, 56 faziam parte do tratamento padrão e 53 do tratamento padrão associado à hidroxicloroquina. de modo que os resultados demonstraram que a administração da hidroxicloroquina não resultou em uma probabilidade significativamente mais alta de conversão negativa do que o tratamento padrão sozinho. Ainda, os efeitos adversos, principalmente gastrointestinais, foram maiores nos pacientes que receberam a hidroxicloroquina.

Mais um estudo que corrobora com tais achados foi um estudo realizado com 1376 pacientes hospitalizados por covid-19 na cidade de Nova York, o qual objetivou avaliar a eficácia do tratamento com hidroxicloroquina. Na ocasião 58,9\% dos pacientes receberam o tratamento com este medicamento e o restante não recebeu, os resultados evidenciaram que não houve diferença significativa no risco de serem submetidos a intubação ou no risco de morte entre os dois grupos e conclui que o uso da hidroxicloroquina não deve ser indicado fora de ensaios clínicos randomizados (GELERIS et al., 2020).

Além destes, outros fármacos têm tido sua atividade contra a SARS-Cov-2 testada in vitro. Um dos estudos, por exemplo, avaliou os antivirais Ribavirin, Remdesivir, Sofosbuvir, Galidesivir, e Tenofovir, os quais demonstraram resultados positivos contra um modelo da RNA-polimerase dependente de RNA da SARS-CoV-2 criado em laboratório, pois tais fármacos foram capazes de se ligar 
firmemente à RNA-polimerase (LFIKY, 2020). Isto evidencia a ampla gama de medicamentos em potencial para tratamento da doença e que requerem mais pesquisas.

Atualmente, o Remdesivir se destaca especialmente entre estes antivirais, pois outros estudos também têm confirmado sua eficácia no controle do COVID-19 in vitro (WANG et al, 2020) e, tendo em vista sua segurança observada até então no seu uso prévio em humanos, é um fármaco em potencial para ser aplicado nos pacientes infectados.

Sob esse viés, um novo estudo randomizado, duplo-cego e controlado por placebo, com 1063 pacientes, em 73 locais envolvendo Estados Unidos, Dinamarca, Reino Unido e entre outros, foi realizado com 541 pacientes recebendo remdesivir e 522 pacientes recebendo o placebo (BEIGEL et al., 2020). A análise primária desse estudo foi um teste log-rank sedimentado do tempo até a recuperação com remdesivir em comparação com placebo, com estratificação por gravidade da doença. Percebeu-se que aqueles que receberam remdesivir tiveram um tempo médio maior de recuperação: 11 dias em comparação com 15 dias naqueles que receberam placebo; assim como evidenciou-se que a mortalidade foi numericamente menor no grupo com remdesivir (7,1\% e 11,9\% nos grupos com remdesivir e placebo, respectivamente). Dessa forma, o estudo possui como desfecho o apoio ao uso do remdesivir em pacientes hospitalizados com COVID-19, porém novas estratégias terapêuticas de combinação com outros agentes antivirais devem ser pesquisadas para melhorar a recuperação dessa doença.

Outra aposta para o tratamento da infecção é a ivermectina, um antiparasitário de amplo espectro aprovado pela FDA (Food and Drug Administration) que, nos últimos anos, têm demonstrado atividade antiviral in vitro (CALY et al, 2020). Um destes estudos avaliou a atividade deste fármaco contra o SARS-CoV-2 in vitro e seus resultados demonstraram que a ivermectina, aplicada $2 \mathrm{~h}$ após a infecção das células, foi capaz de reduzir significativamente a quantidade de RNA viral dentro de $48 \mathrm{~h}$ (GAUTRET et al., 2020). Isto indica que a ivermectina é mais um candidato em potencial para uma investigação mais aprofundada quanto a possíveis benefícios em humanos.

Em um estudo multicêntrico, prospectivo, aberto, randomizado, com 127 pacientes com COVID-19 que foram admitidos em seis hospitais em Hong Kong, buscou-se analisar a terapêutica combinada com lopinavir, ritonavir, ribavirina e interferon beta-1b em comparação com um grupo controle que estava em uso apenas de lopinavir e ritonavir. Com isso, observou-se que o tempo para a negativação do swab nasofaríngeo na RT-PCR para SARS-CoV-2 foi significativamente menor no grupo que recebeu o tratamento combinado em comparação ao grupo controle, com resultado de 7 e 12 dias respectivamente, sugerindo que mais estudos envolvendo a terapêutica antiviral tripla com interferon beta-1b podem vir a ser promissores, haja vista seu potencial demonstrado (HUNG et al., 2020).

Faz-se necessário para todas essas drogas, novos estudos controlados, randomizados e em maior escala para que os resultados possam ser melhor interpretados, e protocolos clínicos possam ser estabelecidos para aplicação no tratamento do COVID-19. 


\section{CONCLUSÃO}

A partir dos dados coletados observa-se que os sintomas mais comuns associados a COVID-19 incluem-se febre, tosse, cefaleia e mialgia. Entretanto é importante compreender que muitos casos podem ser assintomáticos, devendo-se atentar às medidas sanitárias de controle da propagação desta patologia, principalmente entre os grupos mais vulneráveis. Além disso, a dispnéia foi relatada como um dos principais sintomas presentes entre os indivíduos em estágio grave da doença, sinalizando para os cuidados dos serviços de saúde a possibilidade do uso de ventilação mecânica naqueles que apresentam falta de ar como queixa importante. Ademais, estudos comprovam o atual alerta das organizações de saúde no cuidado especial a pessoa idosa, tendo em vista que a taxa de mortalidade do COVID-19 é mais alta entre aqueles com idades mais avançadas.

Para a suspeita da doença, além do forte componente clínico, exames complementares como as imagens da TC de tórax com alterações, características principalmente em se tratando da opacidade em vidro fosco, e alterações laboratoriais em comum entre os pacientes, como linfocitopenia e elevação do D-dímero, tem ajudado no estabelecimento da hipótese diagnóstica para os pacientes sintomáticos. Além disso, a respeito da TC de tórax, este exame tem oferecido um bom método de confirmação diagnóstica. Ou seja, na ausência de testes de RT-PCR, padrão ouro para diagnóstico laboratorial do novo coronavírus, a observação clínica unido ao exame de tomografia computadorizada do tórax pode ter valor diagnóstico, esta afirmação também foi confirmada com estudos envolvendo pacientes gestantes, onde a TC tem apresentado eficácia na confirmação para a suspeita de COVID-19.

Para contribuir com as pesquisas relacionadas à infecção intra-uterina, foi possível observar que assim como as síndromes respiratórias anteriormente vividas pelos seres humanos não há ainda relatado na literatura a possibilidade de transmissão vertical do novo coronavírus. Um ponto positivo, mas que não dispensa o cuidado tanto no pré-natal quanto durante o parto. Apesar disso, sugerem-se novas investigações que abordem a contaminação entre mãe e feto também nas primeiras semanas de gravidez, considerando que os atuais estudos analisados abordaram grávidas que já estavam no terceiro trimestre de gestação.

No que se refere aos possíveis tratamentos para COVID-19, as atuais pesquisas envolvem principalmente o uso de antirretrovirais e antimaláricos, no entanto os resultados permanecem controversos e, até o momento, não existem opções comprovadamente eficazes contra o vírus, tendo em vista que a cloroquina e a hidroxicloroquina, fármacos até então promissores, têm demonstrado ausência de benefícios e efeitos adversos graves, como arritmias e paradas cardíacas. Sendo assim, são necessários estudos clínicos controlados, randomizados e em maior escala para que os resultados possam ser melhor interpretados, e protocolos clínicos possam ser estabelecidos para aplicação no tratamento do COVID-19. 


\section{REFERÊNCIAS}

BEIGEL, J. H. et al. Remdesivir for the Treatment of Covid-19 - Preliminary Report. New England Journal Of Medicine, [s.1.], maio. 2020.

BHATRAJU, PAVAN K.; GHASSEMIEH, BIJAN J.; NICHOLS, MICHELLE; KIM, RICHARD; JEROME, KEITH R.; NALLA, ARUN K. Covid-19 in Critically Ill Patients in the Seattle Region Case Series. New England Journal Of Medicine, [s.1.], mar. 2020.

CAI, QINGXIAN; YANG, MINGHUI; LIU, DONGJING; CHEN, JUN. TEMPORARY REMOVAL: Experimental Treatment with Favipiravir for COVID-19. Engineering, [s.1.], p. 1-7, mar. 2020.

CALY, LEON; DRUCE, JULIAN D.; CATTON, MIKE G.; JANS, DAVID A.; WAGSTAFF, KYLIE M.. The FDA-approved Drug Ivermectin inhibits the replication of SARS-CoV-2 in vitro. Antiviral Research, [s.1.], abr. 2020.

CAO, BIN; WANG, YEMING; WEN, DANNING; LIU, WEN. A Trial of Lopinavir-Ritonavir in Adults Hospitalized with Severe Covid-19. New England Journal Of Medicine, [s.1.], p. 1-13, mar. 2020.

CUMMINGS, M. J. et al. Epidemiology, clinical course, and outcomes of critically ill adults with COVID-19 in New York City: a prospective cohort study. The Lancet, [s.1.], maio. 2020.

EUROPEAN CENTRE FOR DISEASE PREVENTION AND CONTROL. (ECDC), An agency of the European Union. Situation update worldwide. 2020. Disponível em: https://bit.ly/2XLiOH6. Acesso em: $30 / 05 / 2020$

CHEN, J. Pathogenicity and transmissibility of 2019-nCoV-A quick overview and comparison with other emerging viruses. Microbes And Infection, [s.1.], v. 22, n. 2, p. 69-71, mar. 2020.

CHEN-HUI, H. et al. Clinical characteristics and intrauterine vertical transmission potential of COVID-19 infection in nine pregnant women: a retrospective review of medical records. The Lancet, [s.1.], v. 395, n. 10226, p. 809-815, mar. 2020.

CHEN-TAO T. et al. Clinical characteristics of 113 deceased patients with coronavirus disease 2019: retrospective study. Bmj, [s.l.], p. 1091-1103, mar. 2020. 
DEVAUX, C. A. et al. New insights on the antiviral effects of chloroquine against coronavirus: what to expect for COVID-19?. International Journal Of Antimicrobial Agents, [s.1.], p. 1-32, mar. 2020.

GAO, J.; TIAN, Z.; YANG, X. Breakthrough: Chloroquine phosphate has shown apparent efficacy in treatment of COVID-19 associated pneumonia in clinical studies:. Bioscience Trends, [s.1.], v. 14, n. 1, p. 72-73, fev. 2020 .

GAUTRET, P. et al. Hydroxychloroquine and azithromycin as a treatment of COVID-19: results of an open-label non-randomized clinical trial. International Journal Of Antimicrobial Agents, [s.1.], p. 1-24, mar. 2020.

GELERIS, J. et al. Observational Study of Hydroxychloroquine in Hospitalized Patients with Covid-19. Massachusetts Medical Society. New England Journal Of Medicine, [s.1.], maio. 2020.

GUAN, W. et al. Clinical Characteristics of Coronavirus Disease 2019 in China. New England Journal Of Medicine, [s.1.], p. 1-13, fev. 2020.

HUNG, I. F. et al. Triple combination of interferon beta-1b, lopinavir-ritonavir, and ribavirin in the treatment of patients admitted to hospital with COVID-19: an open-label, randomised, phase 2 trial. The Lancet, [s.1.], v. 395, n. 10238, p. 1695-1704, maio. 2020.

LFIKY, A. A. Ribavirin, Remdesivir, Sofosbuvir, Galidesivir, and Tenofovir against SARS-CoV-2 RNA dependent RNA polymerase (RdRp): A molecular docking study. Life Sciences, [s.1.], p. 1-20, mar. 2020.

LINTON, N. M. et al. Incubation Period and Other Epidemiological Characteristics of 2019 Novel Coronavirus Infections with Right Truncation: A Statistical Analysis of Publicly Available Case Data. Journal Of Clinical Medicine, [s.1.], v. 9, n. 2, p. 538-547, fev. 2020.

LIU, H. et al. Clinical and CT imaging features of the COVID-19 pneumonia: Focus on pregnant women and children. Journal Of Infection, [s.1.], p. 1-7, mar. 2020.

LIU-FANG, F. et al. Patients of COVID-19 may benefit from sustained lopinavir-combined regimen and the increase of eosinophil may predict the outcome of COVID-19 progression. International Journal Of Infectious Diseases, [s.1.], p. 1-29, mar. 2020. 
LIU-KUI, K. et al. Clinical characteristics of novel coronavirus cases in tertiary hospitals in Hubei Province. Chinese Medical Journal, [s.1.], p. 1-7, fev. 2020.

LIU-WEI et al. Clinical characteristics of 19 neonates born to mothers with COVID-19. Springer Science and Business Media LLC. Frontiers Of Medicine, [s.1.], v. 14, n. 2, p. 193-198, abr. 2020.

MEHRA, M. R. et al. Hydroxychloroquine or chloroquine with or without a macrolide for treatment of COVID-19: a multinational registry analysis. The Lancet, [s.1.], maio. 2020.

QIU, H. et al. Clinical and epidemiological features of 36 children with coronavirus disease 2019 (COVID-19) in Zhejiang, China: an observational cohort study. The Lancet Infectious Diseases, [s.l.], p. 1-8, mar. 2020.

ROSENBERG, E. S. et al. Association of Treatment With Hydroxychloroquine or Azithromycin With In-Hospital Mortality in Patients With COVID-19 in New York State. Jama, [s.1.], maio. 2020. American Medical Association (AMA).

RUNFENG, L. et al. Lianhuaqingwen exerts anti-viral and anti-inflammatory activity against novel coronavirus (SARS-CoV-2). Pharmacological Research, [s.1.], p. 1-11, mar. 2020.

S, BIALEK; BIALEK, STEPHANIE; BOUNDY, ELLEN; BOWEN, VIRGINIA. Severe Outcomes Among Patients with Coronavirus Disease 2019 (COVID-19) - United States, February 12-March 16, 2020. Mmwr. Morbidity And Mortality Weekly Report, [s.1.], v. 69, n. 12, p. 343-346, mar. 2020.

SCHWARTZ, D. A.; GRAHAM, A. L. Potential Maternal and Infant Outcomes from Coronavirus 2019-nCoV (SARS-CoV-2) Infecting Pregnant Women: Lessons from SARS, MERS, and Other Human Coronavirus Infections. Viruses, [s.1.], v. 12, n. 2, p. 194-210, fev. 2020.

SINGH, A. K. et al. Chloroquine and hydroxychloroquine in the treatment of COVID-19 with or without diabetes: A systematic search and a narrative review with a special reference to India and other developing countries. Diabetes \& Metabolic Syndrome: Clinical Research \& Reviews, [s.1.], v. 14 , n. 3, p. 241-246, maio. 2020.

TANG, W. et al. Hydroxychloroquine in patients with mainly mild to moderate coronavirus disease 2019: open label, randomised controlled trial. Bmj, [s.1.], maio. 2020. 
VADUGANATHAN, M.; VARDENY, O.; MICHEL, T.. Renin-Angiotensin-Aldosterone System Inhibitors in Patients with Covid-19. New England Journal Of Medicine, [s.1.], p. 1-7, 30 mar. 2020. WANG, M. et al. Remdesivir and chloroquine effectively inhibit the recently emerged novel coronavirus (2019-nCoV) in vitro. Cell Research, [s.1.], v. 30, n. 3, p. 269-271, fev. 2020.

WU, Z.; MCGOOGAN, J. M. CHU, M. Characteristics of and Important Lessons From the Coronavirus Disease 2019 (COVID-19) Outbreak in China. Jama, [s.l.], fev. 2020. American Medical Association (AMA).

YAO, X. et al. In Vitro Antiviral Activity and Projection of Optimized Dosing Design of Hydroxychloroquine for the Treatment of Severe Acute Respiratory Syndrome Coronavirus 2 (SARS-CoV-2). Clinical Infectious Diseases, [s.1.], mar. 2020.

YU, N. et al. Clinical features and obstetric and neonatal outcomes of pregnant patients with COVID-19 in Wuhan, China: a retrospective, single-centre, descriptive study. The Lancet Infectious Diseases, [s.1.], v. 20, n. 5, p. 559-564, maio. 2020.

YUEN, K.; YE, Z.; FUNG, S. SARS-CoV-2 and COVID-19: The most important research questions. Cell \& Bioscience volume 10, Article number: 40. 2020.

ZHOU, F. et al. Clinical course and risk factors for mortality of adult inpatients with COVID-19 in Wuhan, China: a retrospective cohort study. The Lancet, [s.1.], v. 395, n. 10229, p. 1054-1062, mar. 2020. 